\title{
The Relation Between Way-Finding and Built Environment Legibility "Effects of Architectural Design Elements on Spatial Behavior"
}

\author{
Ahlam "Mohammad Jamal" Eshruq Labin \\ Architecture Engineering \\ Faculty of Engineering \\ Al al-Bayt University \\ Mafraq, Jordan
}

\begin{abstract}
The study examines issues that affect users' way-finding behavior in any built environment, and explains how this issue affectsthe built environment legibility. The methodology based on reviewing the comprehensive literature, and then a questionnaire survey was conducted to obtain the required data. Faculty of Hajjawy for Engineering Technology at the Yarmouk University was chosen as a case study to launch the survey, the participants were the students who were studying at the faculty. The results show that there are two main groups of factors that affect the way-finding behavior are; Individual factors and Built environment Legibility factors. Moreover, the individual's way-finding behaviour is affected by the built environment legibility factors. The built environment legibility contains several factors as, architectural elements; visual communication elements (graphical); audible communication (verbal) elements and tactile elements.
\end{abstract}

Keywords:Built environment legibility, cognitive mapping, plan configuration, spatial orientation, way-finding.

\section{Introduction}

Where are we? Where are we going? These are two substantive questions that mankind has never given up taking. Way-finding is a vital criterion for human behaviour and spatial orientation; since this need related to the human settlement on the earth. The concept starts with the foundation of life, when the human carved signs on trees and stones, then they used stars to know their location and destination, after that they invented the magnetic compass. The tools to achieve this need, were developed through time, and now we use new technology to know our position and ways like GPS (Jibestream 2014). Good way-finding means the capacity to understand your position, recognizing the sense of the way that conduces to the arrival. Way-finding is more than just signs: it is a coordinated group of aids to help people navigate, throw a mental mapping (Golledge 1999; Karimi \& Emami 2015).

Introducing comprehensive way-finding scheme, architectural design can facilitate user access, increasing satisfaction and reducing confusion. When individuals lost their paths, they may face some problems such as; loss of time to get their way-finding, decreased safety, stress, or irritation. In architecture, the importance of the wayfinding comes from facilitating user access, increasing user's satisfaction, saving time and money, preventing accidents and reducing the confusion of visitors, reducing stress, besides improving health and productivity (Evans \& McCoy 1998). Way-finding is a method to define our destination and reach it, it could be as simple as the circulation at home or complicate as reaching escape ways in the case on fire. The level of complexity of the building becomes less important if familiarity with an environment increase. Likewise, performance in wayfinding improves both in accuracy and latency (O’Neill 1992). Wayfinding can be defined as; "the use of space and environment to find direction in the built environment" (Brandon, 2008). In conclusion, way-finding is the ability to put the "the correct information" in the "correct places" and "legible space" to simplify the circulation system in the built environment (Huelat 2007).

\subsection{Research objectives}

The research aims to

1- Redefine the concept of way-finding.

2- Determine the elements that influence way-finding processes (way-finding tools).

3- Investigate the way-finding tools' impact on the built environment legibility.

4- Investigate the students' way-finding behaviour and built environment legibility at Yarmouk University as a case study. 


\section{Methodology}

The methodology of this research was employed to redefine the concept of way-finding, and to find the relationship between way-finding and other concepts such as built environment legibility. The research methodology started by identifying, formatting, and reviewing the comprehensive literature review of wayfinding's concepts, way-finding strategies, way-finding factors, and finally built environment legibility.

Secondary data on way-finding and built environment legibility were attainmented from a literature review and national datasets. In this work, the background was divided into two sections; the first section overviews the background of way-finding theories; the second section overviews the background of other concepts related to the idea of way-finding such as; way-finding strategies, way-finding factors, and built environment legibility. Then a conclusion was made to form the relationship between them.

A survey was conducted to determine the level of built environment legibility at the building of Faculty of Hajjawy for Engineering Technologyin the Yarmouk University. The level of built environment legibility affects the students' way-finding behaviour.

The recent study based on two stages to obtaining the required data:

First stage: based on the existing research and literature review to get the secondary data to identify the wayfinding briefly and concluded the main factors that affect the way-finding behaviour.

Second stage: The survey, based on the secondary data that were obtained from the literature review a questionnaire was organized, it contains two groups of questions are;

1.Individual factors which include; individuals' age, individuals a' gender, individuals' health, and individuals' culture.

2.Built environment Legibility factors such as; Architectural elements; visual communication elements (graphical); audible communication (verbal or oral) elements and tactile elements then data were collected via a questionnaire and analyzed by using the SPSS statistical program.

\subsection{Participants}

Students in the Faculty of Hajjawy for Engineering Technology were recruited to fill a questionnaire about the factors that affect their way-finding behaviour. Thus, these factors have an impact on the built environment legibility.All of the students are familiar with the building and they are from several departments such as; Electronics Engineering, Communications Engineering, Computer Engineering, Electrical Manpower Engineering, Systems Engineering, Medical and Biomedical Informatics, Civil Engineering, Architecture, Industrial Engineering. The number of the participants is 120 responded participants; 40 male and 80 female.

\subsection{Yarmouk University (YU)}

Yarmouk University is a public university, comprehensive and state-supported university located near the city centre of Irbid, in northern Jordan. The University consists of fifteen faculties are; faculty of arts, faculty of science, faculty of economics and administrative science, Hijjawy faculty for engineering technology, faculty shareaa, faculty of education, faculty of physical education, faculty of fine arts, faculty of mass communication, faculty of information technology and computer science, faculty of archaeology and anthropology, faculty of tourism and hotel management, faculty of law, faculty of medicine and faculty of pharmacy.

YU campus is located in the second-largest city in Jordan. The campus consists of independent buildings for each faculty and administration unit. Hajjawy Faculty for Engineering Technology faculty at the Yarmouk University was chosen as a case study to launch the survey.

The faculty was established in 1984 with a generous donation from the Hisham Adib Hijjawi to graduating engineers with a high level of knowledge and practical skills in the fields of engineering and information technology.

\subsection{Questionnaire structure}

The questionnaire is grouped into two clusters of questions are; Individual factors and Built environment Legibility factors. The individual's data include (Table 1); the participants' gender, the participants' age, the participants' scientific specialization, the participants' nationality and the participants' health. The built environment Legibility factors (Table 2) include: Firstly, the architectural elements, which can be grouped into; First elements is the design language as; the availability of landscape, landmarks, pedestrian' routs, the plan layout 
and the building configuration. Second elements are, the spatial organization and circulation system as; the accessibility to staircases, elevators and corridors, also the availability of nods and intersection spaces. The third group of elements is the sitting appearance, which includes; the use of several colours, materials, decoration, textures and lighting system for several departments at the faculty.

Secondly, the availability of visual communication or graphical elements, for example; the use of maps, 'you are here' map, direction signs, written signs, painting guides, offices' number, halls' number, floors' number, and a digital display device.

Audible or verbal communication tools, such as; the affordability of information stations, audible chimes inside elevators and audible signs. Finally, the tactile elements, which contains; the use of writing Braille, the availability of special flooring and prominent boards.

\section{The way-finding theories}

Some theories related to the concept of way-finding as Lynch's book, in 1960 or the cognitive map theory for Tolman from 1948 to 1973 . Way-finding is a method to define the destination and reach our; it could be as easy as moving from one room to another at the home or as difficult as trying to escape a building on fire. The level of complexity of the building becomes less important if familiarity with an environment increase. Likewise, performance in way-finding improves both in accuracy and latency (O'Neill 1992).

The image of the city was a book for Kevin Lynch, the concept of way-finding was introduced in 1960.In his book, he studiedthe way-finding 'equipment, such as; signs arrow, number, street name and city guide signs focusing on routes, nodes, edges, landmarks and areas to understand the perceptual spatial experience way-finding in the urban environment, such as; "spatial orientation" and "cognitive map".

A cognitive map is an internal representation of environmental information, whereas, cognitive mapping process expresses the internal manipulation of data in the form of spatial choice and decision-making of human wayfinding through environments (Golledge 1999). Generally, the way-finding process requires a mental photography abstraction of the built environment for creating a cognitive map used to solve positioning problems (Huelat 2007).There are numerous factors affect the personal cognitive and movement behaviour, which are considered as guidelines that control human spatial decisions such as; maps, written descriptions, image representation. Navigation by humans based on two methods; piloting and orientation. Piloting is to set the individuals' position, while the orientation is to determine their movement direction by using the landmarks (Golledge 1999; Karimi \& Emami 2015).

In 1973-1982, Downs and stea-Kaplan studied the individual decision-making process based on the relation between cognitive map and the process-oriented approach. Also, Passini (1984) combined the architecture approach and cognitive science.People navigation is affected by various variables, as; individual differences, gender, age, cultural and differences in the health of people. The individual differences affect people way-finding abilities; these differences include culture, health, IQ, gender, and age (Karimi \& Emami 2015). Salthouse,Arthur, Hancock, Chrysler, Anooshian and Young studied the effect of the age differences in the way-finding. Children 12 years and older can learn the route easily; while children under 10 years are easily lost(Cornell et al. 1994). Salthouse (1991) found that the ability of older people to find their routes are weak; because they may associate diseases with increasing age.Carrol (1993)concluded that a strong relation founded between way-finding ability and IQ. In 1997, Arthur, Hancock and Chrysler noted that adult men are superior in the explanation of data; as they follow adopted strategies than women (Anooshian \& Young 1981). Women strategies are more accurate; as they focus on signs. Whereas; men's approach for navigation is appropriate (Chen et al.1994a, 1996b, 2009).

Another experiment was conducted by Alycia (2009) to investigate the variations between men and women on finding their routes, and the factors that relate to way-finding strategies. The outcomes indicated that; when males and females based on cardinal directions than the usingof landmark directions, they will be faster and more precise. Moreover, individuals will make more navigation mistakes if they havemore spatial nervousness(Chen et al. 2009).

Way-finding is affected also by cultural differences obviously (Kearins 1981). Besides, the differences in health, for example; people with visual deficiencies are weak in the way-finding. Thus, the architectural solutions for the problem are obliquefundamentals, angled and bowed avoided, split the large open space into small parts, use of signs, use illumination, flooring, texture, and improved the visual and tactile elements (Rousek \& Hallbeck 2011). One of the issues that affect human navigation decision is the space syntax process; Hölscher (2011) investigated human navigation decision by using route-based space syntax with cognitive issues which means the users' level 
of prior knowledge. An experiment was conducted by making a comparison between the way-finding behaviour of inexperienced and experienced participants. The results showed that the experienced participants avoided the unnecessary path. While inexperienced participants knowing less detailed data about the environment.

In their navigation decision, they utilized the central point strategy as; clear information and relatively known building parts like entrances and corridors.

\section{Way-finding strategies}

Several studies were conducted to investigate the environmental variables that form way-finding strategies such as visual access, the distinction on using architectural design, the use of signs and room numbers, and floorplan configuration (Weisman's 1981), and the familiarity with the space; as the visual access has an impact on the individuals' spatial behaviour(Gärling et al. 1983).

Based on the literature review; way-finding process follows a three-stage strategy. This strategy starts by taking decisions and developing plans. Secondly, implementing the agenda and affirmed to make a fitting place and behaviour. The final step is to processing of thedata that encompass identifying the environment (Arthur \& Passini 1992; Karimi \& Emami 2015).

Another researcher such as; Allen and Huelat concluded that; the way-finding process includes: Oriented Search, trail following, piloting, path integration, habitual movement and cognitive map (Allen 1999). Huelat (2007) found that the way-finding process follows various factors are: knowing where you are, identify the destination and situation, identify the route to the destination, the correct route based on the environment data. Eventually, reaching the destination.

Karimi and Emami classified way-finding strategies into six approaches:

1.Graph approach to get a sequential movement (Lynch1960; Meilinger2008).

2.Verbal communication approach based on a communication skill (Hoscher et al. 2011).

3.Landmarking approach (Maguire \& Spiers 2008).

4.Cognitive map approach (Tolman 1948; Golledge 2004)

5.Direction approach, North, South, East and West (Dalton 2003; Maguire \& Spiers 2008; Raubal \& Wintet 2002).

6.Angle approach;the grid street systemdelivers more to the angled street (Kaplan 1975).

Depending on the way-finding ability, individuals can be classified into four clusters are; individuals who based on written directions and maps, individuals who used verbal communication about directions, persons who rely on visual communication as colours and signs, and the final group who based on communication with other persons to gain the required data for way-finding (Allen 1999). Arthur \& Passini stated that people may use various ways to get the information about the environment; that implies people can find their way through different procedures from above categories (Arthur \& Passini 1992; Carpman \& Grant 2001).Understanding the factors that affect the way-finding process will eliminate the users' problem that possibly face them in the built environment. Wayfinding elements can be classified into four groups of parts are(Table 3); oral, architectural, graphical, and tactile elements(Sims, 1991; Muhl \& Hausen, 2006). Way-finding utilized a collection of tools as the assistance of people to find their final destinations in an inexperiencedsetting(Dogu\&Erkip 2000).

The physical factors that affect the way-finding procedure can be classified into two major groups: the plan's layoutwhich contains the spatial content ofan environment, organization, form, and circulation. And the second group is the environmental information's quality; it contains theexpressions ofgraphical and architectural issuesneeded for information necessary to solve way-finding problems (Passini et al. 1998).

\section{Built environment Legibility}

Way-finding system based on the spatial configuration of a structure to elicit the appropriate information, so a place with a high legibility factor facilitates the obtaining of environmental information. Legibility of space can be defined as; Individuals' simplicity of organizing the pictorial information that was obtained from the surrounding environment in the form of a coherent basis for action (Dogu \& Erkip 2000).

The human ability to have a shortcut is considered an indication of an individual's understanding of the built environment or the degree of familiarity with it(Golledge 1999; Dogu \& Erkip 2000). Some individuals navigating in an indoor environment relied heavily on the clearness of the spatial organization of the building and the obvious architectural elements. However, others depend on signage, colours, and lighting systems (Baskaya et al. 2004). 
Architectural elements affect the spatial organization, such as entries, key landmarks, besides vertical and horizontal circulation system. It is considered as a requirementofthe spatial organization understands of anystructure. If the sittings weren't understood, and have not a clear spatial organization;then it does not help with way-finding and has a low legibility factor (Hillier \& Hanson 1988; Arthur \& Passini 1992; Dogu \& Erkip 2000). Arthur and Passini concluded several components that bear on the built environment legibility (Table 4).

Poor wayfinding performance occurs because of some design elements such as; repetitive architectural features, unclear circulation patterns, conflicting articulation of interior and outside places, and many undistinguished entrances. Arthur and Passini (1992) assumed the positive way-finding process must have the challenge of design the interesting sitting that have a dramatic experience and safe, approachable, and way-finding-efficient, despite the complexity of the design. Hölscher,Tenbrink and Wiener concluded that there is a relation between human spatial cognition and the architectural design; since spatial features affect the people's cognitive approaches and route choice behaviour.Legibility in the built environment significantly reduced user confusion, anger, perceived crowding, and overall emotional discomfort (Wener \& Kaminoff 1983). The degree of familiarity with a built environment affects the individual way-finding behaviour; so individuals rarely faced disorientation in a familiar environment. Legibility affected by recognition of places; if the environment is familiar, individual can recognize the places. There are several ways to orient individuals in an unfamiliar environment as; maps and signs (Dogu \& Erkip 2000). Weisman (1981) specified the environmental variables that suffer from way-finding procedure. He categorized them into four groups are: (a) visual access to landmarks inside and outside a structure, (b) The ability to recall based on thecontrast on the architectural design between different areas, (c) the using of signs and room numbers to supplysitting identifying, and (d) the form of the building (configuration), which can affect the individuals'understanding of the external building's layout.

The ability to remember anystructure and its position relies on the crowded around the building, its shape, height, and the physical attributes (Evans et al. 1982). This emphasis on the significance of distinguishing places by using several ways as; the building form, define the architectural features, several decorative elements, textures, material, light, and colours (Arthur \& Passini 1992).

The circulation is considered as the main organizing force that affects the way-finding process; it can be defined as space thatused to move, to find the way, and to make a decision to proceed way-finding (Arthur \& Passini 1992). The configuration of a building helps individuals to build a cognitive map (mental image) that affects way-finding behaviour. Thus, the complexity of the plan configuration affects way-finding performance. A study explained that the number of students that being lost in the simple and legible plan is less than in the complex one (Weisman 1981; O'Neill 1991b; Haq \& Zimring 2003).Individuals can form cognitive maps easily based on the simplicity of the plan, Symmetry, regularity, continuity, simple corridor systems and central atrium systems, since the users can capture the visual access easily in the central open-plan (Lawton et al. 1970; Weisman 1981; Canter 1996; Dogu \& Erkip 2000).Three factors affect way-finding in an unfamiliar environment are; orientation, route, and building configuration (Lawton 1996). Other ways may help people in an unfamiliar environment as prior knowledge about the building; as using the maps. Identity or the pictorial image of the building is as important as the good floor plan; as it differentiates the building from the surrounding (Abu-Obeid 1998; Murakoshi \&Kawai 2000).

Many architects believed that adding signs to a building is not compatible with a lack of architectural integrity (Sims, 1991). The signs can be classified into four main types are: direction signs, information signs, identification signs and warning signs. Some researcher suggested that, the position where signage is placed improved way-findingperformance; whereas the best position is the decision points (such as the intersection of two corridors). Otherwise, O'Neill (1991a) found that the plan configuration is more significant than the signage position (Muhl \& Hausen 2006).

Some architectural elements that help in way-finding process as; identify arrival place, offer anreachable walkways and a appropriate parking near to public entry, information stations within the public entry, identify elevator lobbies to facilitate the visual access, using constant lighting system, distinctive tile flooring and architectural finishes in the main public corridors, using of memorable landmarks especially inthe main intersection points and main corridors, design waiting zoneswith a visual connection to corridors, using varied colours, varied lighting system, and varied finishes to distinguish between public and non-public corridors, and finally harmonize level numbers between joining buildings (Muhl \& Hausen 2006). 


\section{Discussion}

Based on the literature review, the study can conclude several concepts and factors that affect the way-finding process (table 5).The study categorized the factors that bear on the way-finding process into two main categories are (figur1):

1.Individual factors which include; individuals' age, individuals' gender, individuals' health, individuals' culture, and Individuals' IQ.

2.Built environment Legibility factors such as; Architectural elements; visual communication elements (graphical); audible communication (verbal or oral) elements and tactile elements

Architectural elements can be classified into; Design language, spatial organization and sitting appearance. Design language includes mainly landmarks, plan layout and the building configuration, while the spatial organization takes into consideration variable issues as; horizontal and vertical circulation systems, entrances, corridors, nods and spaces. Sitting appearance includes; colours, textures and lighting schemes.

The visual communication elements or graphical elements contain all types of maps, painting guide, signs, written directions and digital display devices. To achieve an effective visual communication, there are several guidelines should be taken into consideration: using names for all buildings, using simple language, appropriate size for signs and littering, suitable colours and letter form, using "you are here" maps or detailed map for complex plan layout, using maps in the parking, entrances, and interior intersection points, use orient map with building plan layout,use coding spaces by using colours and memorable graphics, use a floor numbering system at the main entry decision points, and use a constancy signs and graphics layout system (Jibestream 2014).

While audible communication interpreted through verbal instructions, it contains elements as; kiosks, elevator chimes, information stations and water fountains. For effective audible communication, in that respect are several instructions are; affording all public entrances and information desks with attendant trained who are familiar with the facility. Provide self-help telephones. Deliver patient-transport personnel to guide visitors. Use audible chimes inside elevators. Using audible landmarks like water fountains. Offer audible signs (Jibestream 2014; Karimi \& Emami 2015).Tactile communication elements include the tools that were practiced to assess the disabled people as; prominent boards, writing Braille and special flooring. To provide tactile tools into the way-finding: Fix "rumble strips" at the stairs and escalators. Use audio-tactile maps at public entrance lobbies. Provide Braille and raised letters in elevators or signs. Using knurled doorknobs. And connect main destinations and data areas with "trails" via materials having differing resilience, like concrete and carpet (Jibestream 2014).

\section{Results}

A survey was conducted to determine the level of built environment legibility at the building of Hajjawy Faculty in the Yarmouk University. The level of built environment legibility affects the students' way-finding behaviour. The questionnaire is grouped into two clusters of questions are; Individual factors and Built environment Legibility factors. Then data were analyzed by using the SPSS statistical program. The first part of the analysis searches in the students' individual factors which include; age, gender, health, and culture. The results show that; there were 120 responded participants; 40 male and 80 female, most of the students at the age of 23-24 years (Table 6). 54\% of the participants are students at the architectural department, $17 \%$ of the participants are students at the civil department, and 3\% of them are pupils in the industrial department (Table 6). 41 students are Jordanian while 3 of the students from other nationalities (Table 6). 93\% of the students enjoy good health, while $7 \%$ of the students suffer from health problems (Table 6).

The second section of the analysis search in Built environment Legibility factors, such as; Architectural elements; visual communication elements (graphical); audible communication (verbal or oral) elements and tactile elements. The architectural elements (Table 7), can be classified into several groups; the First group is the design language as; the availability of landscape, landmarks, pedestrian's routs, the plan layout and the building configuration. The results show that $50 \%$ of the participants believed that there are acceptable landmarks amenities available inside the university campus.43.2\% of the participants thought that there are acceptable landscape amenities available in the university campus, while $43.2 \%$ of the participants assumed that there isn't landscape service, and $6 \%$ said that there is a good landscape facility. $50 \%$ of the participants believed that the availability of pedestrian routs is acceptable.40.9\% of the participants believed that the using of symmetrical plan affects their way-finding behaviour, while $38.6 \%$ assumed that this issue was not available, and only $20.5 \%$ of the students believed that it was available in a good manner. 
About the building configuration; $52.3 \%$ of the participants believed that it was available in an acceptable manner between the buildings, while $31.8 \%$ assumed that this issue was not available, and only $15.9 \%$ of the students believed that it was available in a good manner.

The second group of architectural elements contains the spatial organization and circulation system as; the accessibility to staircases, elevators and corridors, also the availability of nods and intersection spaces. Regarding the availability of the stairs; $47.7 \%$ of the participants believed that it was available in an acceptable way, while $18.2 \%$ assumed that this issue was not available adequately, and only $34.1 \%$ of the students believed that it was available in a good adequately.50\% of the participants believed that the stairways were available in an acceptable manner, while $38.6 \%$ assumed that this issue was not available adequately, and only $11.4 \%$ of the students believed that it was available in a good adequately.55\% of the participants believed that the corridors were available in an acceptable manner, while $9 \%$ assumed that this issue was not available adequately, and only $36 \%$ of the students believed that it was available in a good adequately.About the availability of nods; $54.5 \%$ of the participants believed that it was available in an acceptable manner, while $29.5 \%$ assumed that this issue was not available adequately, and only $15.9 \%$ of the students believed that it was available in a good adequately.

The third group of architectural elements is the sitting appearance, which includes; the use of several colours, materials, decoration, textures and lighting system for several departments at the faculty.Only $16 \%$ of the participants assumed that the use of various colours, to distinguish between the departments, was available in an acceptable way, while the majority $73 \%$ expected that this issue was not used adequately, and only $11 \%$ of the students believed that it was available in a good adequately. $29.5 \%$ of the participants believed that different materials were used, to distinguish between the departments, was available in an acceptable manner, while the majority $68.2 \%$ assumed that this issue was not used adequately, and only $2.3 \%$ of the students believed that it was available in a good adequately. $27.3 \%$ of the participants believed that different decoration systems were used among the departments, to distinguish between them, were available in an acceptable manner, while the majority $72.7 \%$ assumed that this issue was not used adequately. $40.9 \%$ of the participants believed that different textures were used, to distinguish between the departments, was available in an acceptable manner, while the majority $52.3 \%$ assumed that this issue was not used adequately, and only $6.8 \%$ of the pupils believed that it was available in a good adequately. $34.1 \%$ of the participants believed that different lighting systems were used among the departments, was available in an acceptable way, while the majority $54.5 \%$ assumed that this issue was not used adequately, and only $11.4 \%$ of the students believed that it was available in a good adequately.

The survey studies the accessibility to the circulation system (Table 8) as the stairs' position and the elevators' position. The results show that; the majority $50 \%$ of the students assumed that the position of the stairways was easily accessible; whereas the majority assumed that the positions of both elevators and entrances were needed to search. But the minority said that they were not accessible.

The second factors that affect built environment legibility is the availability of visual communication or graphical elements (Table 9), for example; the use of maps, 'you are here' map, direction signs, written signs, painting guides, offices' number, halls' number, floors' number, and digital display device. The outcomes show that $18.2 \%$ of the participants believed that maps that explain the building functions were available in an acceptable manner, while $79.5 \%$ assumed that this issue was not available adequately and only $2.3 \%$ of the students believed that it was available in a good adequately.9.1\% of the participants believed that 'You Are Here' map, which explains where you are, was available in an acceptable manner, while $88.6 \%$ assumed that this issue was not available adequately, and only $2.3 \%$ of the students believed that it was available in a good adequately.

$15.9 \%$ of the participants believed that the direction signs as; right and left directions, was available in an acceptable manner, while the majority $84.1 \%$ assumed that this issue was not available adequately. $38.6 \%$ of the participants believed that the written signs as; right and left directions, were available in an acceptable way, while the majority $61.4 \%$ assumed that this issue was not available adequately.

$15.9 \%$ of the participants believed that the painting guides, was available in an acceptable manner, while $79.5 \%$ assumed that this issue was not available adequately, and only $4.5 \%$ of the students believed that it was available in a good adequately. $22.7 \%$ of the participants believed that the offices' numbers were available in an acceptable manner, while $11.4 \%$ assumed that this issue was not available adequately, and the majority $65.9 \%$ of the students believed that it was available in a good adequately. $13,6 \%$ of the participants believed that the halls' numbers were available in an acceptable manner, while $22.7 \%$ assumed that this issue was not available adequately, and the majority $63.6 \%$ of the students believed that it was available in a good adequately. $25 \%$ of the participants 
believed that the floors' numbers were available in an acceptable manner, while $15.9 \%$ assumed that this issue was not available adequately, and the majority $59.1 \%$ of the students believed that it was available in a good adequately.45.5\% of the participants believed that the digital display devices were available in an acceptable manner, while $43.2 \%$ assumed that this issue was not available adequately, and the minority $11.4 \%$ of the students believed that it was available in a good adequately.

The third factor that affects the built environment legibility is the Audible or verbal communication tools (Table $10)$, such as; the affordability of information stations, audible chimes inside elevators and audible signs. The majority of the participants, $86.4 \%$ assumed that the information stations were not available adequately, and the minority of the students, $2.3 \%$ believed that it was available in a good adequately. While, $11.4 \%$ of the students believed that it was available in an acceptable manner.The majority of the participants, $93.2 \%$ assumed that the audible chimes inside elevators were not available adequately, and the minority $2.3 \%$ of the students believed that it was available in a good adequately. While, $4.5 \%$ of the students believed that it was available in an acceptable manner.The majority of the participants, $86.4 \%$ assumed that the Audible Signs were not available adequately, and the minority $13.6 \%$ of the students believed that it was available in an acceptable manner.

The final factor that affects the built environment legibility is the tactile elements (Table 11), which contains the use of writing Braille, the availability of special flooring and prominent boards. The results show that the majority of the participants, $61.4 \%$ assumed that the Written Braille signs were not available adequately, and the minority, $38.6 \%$ of the pupils believed that it was available in an acceptable manner.

About the using of special flooring inside the building, $93.2 \%$ assumed that it was not available adequately, and the minority, $6.8 \%$ of the students believed that it was available in an acceptable manner.And regarding the using of prominent boards inside the building, the majority of the participants, 93.2\% assumed that it was not available adequately, and only $6.8 \%$ of thestudents believed that it was available in an acceptable manner.The way-finding

tools that are available in a good manner in Hajjawii Faculty, and have the highest percentages are; offices' numbers, floors' numbers and halls' numbers. While, the way-finding tools that are available in an acceptable manner, but it doesn't enough and need to improve are; the landmarks, the landscape, pedestrian paths, building configuration, staircases, elevators, nods and Digital Display Device. The tools that not found at all are; colours, materials, decoration, textures, lighting system, maps, 'you are here' map, direction signs, written signs, painting guides, information stations, audible chimes inside elevators and audible signs (Table 12).

\section{Conclusion}

In general, the key purpose of way-finding is to report individuals of their settings, by supplying information at important points, tolead them in the right way to their destination. Individuals' way-finding behaviour is affected by two main groups of factors are; Individual factors and built environment legibility factors.Individual factors include; individuals' age, individuals' gender, individuals' health, individuals' culture, and Individuals' IQ. While the built environment legibility is affected by several factors are Architectural elements; visual communication elements (graphical); audible communication (verbal) elements and tactile elements.Based on the questionnaire outcomes there aretwo groups of factors that affect the students' way-finding behaviour in Hajjawyfor engineering technology faculty at the Yarmouk University. The first group is; Individual factors which include; age, gender, health, and individuals' culture. And the second group contains built environment legibility factors, such as; Architectural elements; visual communication elements (graphical); audible communication (verbal or oral) elements and tactile elements.

There are only three way-finding tools, based on the study, that are available in a good manner in Hajjawii Faculty, are; offices' numbers, floors' numbers and halls' numbers. While, ten way-finding tools are available in an acceptable manner, but it doesn't enough and needs to improve are; landmarks, landscape, pedestrian routes, building configuration, Stairs, Elevators, nods and Digital Display Device.

Most of the tools that are used at the study are not found at all in Hajjawy for engineering technology faculty as; the use of various colours between several departments, the use of various materials, the use of various decoration system, the use of various wall textures, the use of various lighting system, the use of maps in the building, the use of 'you are here' map, the use of direction signs and written signs, the use of painting guides, the use of information stations, the use of audible chimes inside elevators and the use of audible signs. Thus, the study concludes that the built environment legibility in faculty of Hajjawy for engineering technology at the Yarmouk University could be not clear; since most factors that affect the students' way-finding behaviour were not available. 
As a conclusion, there is a relation between built environment legibility and the way-finding; since the wayfinding behaviour is affected by built environmental legibility factors. There are nine characteristics for effective way-finding are; memorable, clear, tactile, bright, consistent, heard, specific, common and distinctive.

Memorable is achieved by using memorable landmarks. Clear is applied by utilizing a simple language. Tactile is achieved by using numerous ground coverings and finishing materials to distinguish primary. Bright is achieved by using high contrast colour. Consistency is achieved by using reliable information hierarchies with all signage system. Heard is achieved by using audible sounds at intersection areas. Specific is achieved by using names for the settings and destinations. And Common is achieved by applying accepted and familiar iconography where appropriate. Finally, Distinctive is achieved by using a unique way-finding system and design elements that enhance the personality and identity.

Table 1. Individual factors

\begin{tabular}{|c|c|c|c|c|}
\hline Gender & 1. Male & 2. Female & & \\
\hline Age & 1. $18-20$ & 2. $21-22$ & 3. $23-24$ & 4. $25-26$ \\
\hline Department & 1-Architecture & 2-Civil & 3-Computer & $\begin{array}{l}\text { 4- } \\
\text { Telecomunic. }\end{array}$ \\
\hline & 5-Electrical power & 6-Electronic & 7-Biomedical & 8-Industrial \\
\hline Nationality & 1. Jordanian & 2. Others & & \\
\hline Health & 1. Good health & $\begin{array}{ll}\text { 2. } & \text { Some } \\
\text { problems }\end{array}$ & $\ldots$ & \\
\hline
\end{tabular}

Table 2. Built environment Legibility factors

\begin{tabular}{|c|c|c|c|}
\hline \multicolumn{4}{|c|}{ Architectural elements } \\
\hline Tools & Good availability & Acceptably available & Not available \\
\hline \multicolumn{4}{|l|}{ Especial landmark } \\
\hline \multicolumn{4}{|l|}{ Especial landscape } \\
\hline \multicolumn{4}{|l|}{ Pedestrian route (outside) } \\
\hline \multicolumn{4}{|l|}{ Symmetrical plan } \\
\hline \multicolumn{4}{|l|}{$\begin{array}{l}\text { Especial building } \\
\text { configuration }\end{array}$} \\
\hline \multicolumn{4}{|l|}{ Staircases } \\
\hline \multicolumn{4}{|l|}{ Elevators } \\
\hline \multicolumn{4}{|l|}{ Corridors } \\
\hline \multicolumn{4}{|l|}{ Nods } \\
\hline \multicolumn{4}{|l|}{ Various colours } \\
\hline \multicolumn{4}{|l|}{ Various materials } \\
\hline \multicolumn{4}{|l|}{ Various decorations } \\
\hline \multicolumn{4}{|l|}{ Various textures } \\
\hline \multicolumn{4}{|l|}{ Various lighting systems } \\
\hline \multicolumn{4}{|c|}{ Visual communication elements (graphical) } \\
\hline Tools & Good availability & Acceptably available & Not available \\
\hline \multicolumn{4}{|l|}{ Maps } \\
\hline \multicolumn{4}{|l|}{ "You are here" map } \\
\hline \multicolumn{4}{|l|}{ Direction Signs } \\
\hline \multicolumn{4}{|l|}{ Written signs } \\
\hline \multicolumn{4}{|l|}{ Painting guides } \\
\hline \multicolumn{4}{|l|}{ Office numbers } \\
\hline \multicolumn{4}{|l|}{ Hall numbers } \\
\hline \multicolumn{4}{|l|}{ Floor numbers } \\
\hline \multicolumn{4}{|l|}{ Digital display device } \\
\hline \multicolumn{4}{|c|}{ Audible communication (verbal or oral) } \\
\hline Tools & Good availability & Acceptably available & Not available \\
\hline
\end{tabular}




\begin{tabular}{|c|c|c|c|}
\hline Information stations & & & \\
\hline \multicolumn{4}{|l|}{$\begin{array}{l}\text { Audible chimes inside } \\
\text { elevators }\end{array}$} \\
\hline \multicolumn{4}{|l|}{ Audible signs } \\
\hline \multicolumn{4}{|c|}{ Tactile elements } \\
\hline Tools & Good availability & Acceptably available & Not available \\
\hline Writing Braille & & & \\
\hline Special flooring & & & \\
\hline Prominent boards & & & \\
\hline
\end{tabular}

\begin{tabular}{|c|c|c|}
\hline \multicolumn{3}{|l|}{ The position of staircases is } \\
\hline 1-Strongly accessible & 2-Need to search & 3- Not accessible \\
\hline \multicolumn{3}{|c|}{ The position of the elevators is } \\
\hline 1-Strongly accessible & 2-Need to search & 3- Not accessible \\
\hline \multicolumn{3}{|l|}{ The position of entrances is } \\
\hline 1-Strongly accessible & 2-Need to search & 3- Not accessible \\
\hline
\end{tabular}

Table 3, way-finding elements by Muhl\&Hausen 2006

\begin{tabular}{|c|c|}
\hline Parts & Sections \\
\hline Architectural parts & Colour, texture, signs, space, which leads the required data for way-finding \\
\hline Graphical parts & Maps print, paintings guide, kiosks, signs and digital display devices \\
\hline Oral parts & Information officers or guide for patients \\
\hline Tactile parts & $\begin{array}{c}\text { Used to strengthen the other features and simplify way-finding those with } \\
\text { disabilities, containing blindness or low vision to be handled; by using } \\
\text { writing Braille, prominent boards, and special flooring }\end{array}$ \\
\hline
\end{tabular}

Table 4, Architectural way-finding parts (Source: Arthur and Passini, 1992)

\begin{tabular}{|c|c|c|}
\hline Aims & Parts & Elements \\
\hline \multirow[t]{3}{*}{$\begin{array}{l}\text { Clear articulation \& } \\
\text { coherent grouping of } \\
\text { and interior and exterior } \\
\text { spaces }\end{array}$} & Modelling site and sitting & $\begin{array}{c}\text { Landscaping } \\
\text { Terming roadways } \\
\text { Entrances/exits } \\
\text { Pedestrian routes sidewalk } \\
\text { Pathways }\end{array}$ \\
\hline & $\begin{array}{l}\text { Architectural features and } \\
\text { form of the building }\end{array}$ & $\begin{array}{c}\text { Building form } \\
\text { Building volumes } \\
\text { Physical separation or } \\
\text { Clustering of component } \\
\text { Roof design } \\
\text { Placements of openings } \\
\text { Cladding(skin), materials, textures, } \\
\text { Colours } \\
\text { Decoration and ornamentation } \\
\end{array}$ \\
\hline & Interior spaces' articulations & $\begin{array}{l}\text { Programmatic organization } \\
\text { Spatial unites' definition } \\
\text { Destination zones' definitions } \\
\text { Interior design }\end{array}$ \\
\hline $\begin{array}{l}\text { Legible circulation } \\
\text { system design }\end{array}$ & $\begin{array}{l}\text { External and internal } \\
\text { circulation system design }\end{array}$ & $\begin{array}{c}\text { Design ideas (paths, markers, nodes / } \\
\text { intersections, edges/links) } \\
\text { Approach from street } \\
\text { Roadways } \\
\text { Parking } \\
\text { External paths and walkways } \\
\text { Entrances and exits }\end{array}$ \\
\hline
\end{tabular}




\begin{tabular}{|c|c|c|}
\hline \multirow{4}{*}{} & & Connection to mass transportation \\
\cline { 2 - 3 } & Level change device & Elevators \\
& & Staircases \\
\cline { 2 - 3 } & Internal transportation & Escalators \\
\hline Integrating & Information way-finding & Pobility aids \\
communication system & Pesign & Fixed rail system \\
& & Environmental graphics \\
& & Sign systems \\
& & Orientation devices \\
& & You are there maps \\
& & Real-time information designs \\
\hline
\end{tabular}

Table 5, way-finding tools

\begin{tabular}{|c|c|c|}
\hline Research & Concept & Tools \\
\hline $\begin{array}{l}\text { Kevin Lynch, } \\
1960\end{array}$ & $\begin{array}{l}\text { Space perception \& } \\
\text { way-finding } \\
\text { equipment, } \\
\text { routes, nodes, edges, } \\
\text { landmarks, spatial } \\
\text { orientation \& } \\
\text { cognitive map } \\
\end{array}$ & $\begin{array}{l}\text { Signs arrow, number, street name and city guide } \\
\text { signs }\end{array}$ \\
\hline $\begin{array}{c}\text { Downs \&stea- } \\
\text { Kaplan, 1973-1982 }\end{array}$ & $\begin{array}{c}\text { decision-making } \\
\text { process }\end{array}$ & Cognitive map and the process-oriented approach \\
\hline $\begin{array}{l}\text { Anooshian\& Young, } \\
1981\end{array}$ & Way-finding abilities & Gender differences \\
\hline Kearins, 1981 & Way-finding abilities & Cultural differences \\
\hline Weisman, 1981 & $\begin{array}{l}\text { Environmental } \\
\text { variables }\end{array}$ & $\begin{array}{l}\text { Visual access, ability to recall based on the } \\
\text { architectural differentiation, the use of signs and } \\
\text { room numbers, and building configuration }\end{array}$ \\
\hline Passini, 1984 & Way-finding approach & \\
\hline Salthouse, 1991 & Way-finding abilities & The age differences \\
\hline Sims, 1991 & Way-finding elements & $\begin{array}{c}\text { Architectural elements, graphical elements, oral } \\
\text { elements and tactile elements }\end{array}$ \\
\hline $\begin{array}{l}\text { Arthur \&Passini } \\
1992\end{array}$ & $\begin{array}{l}\text { Way-finding } \\
\text { information }\end{array}$ & $\begin{array}{c}\text { Design language } \\
\text { Poor way-finding performance (repetitive } \\
\text { architectural features, unclear circulation patterns, } \\
\text { conflicting articulation of interior and exterior } \\
\text { spaces, and many undistinguished entrances). } \\
\text { positive way-finding process }\end{array}$ \\
\hline $\begin{array}{l}\text { Gross \&Zimring, } \\
1992\end{array}$ & $\begin{array}{l}\text { Way-finding in an } \\
\text { unfamiliar } \\
\text { environment }\end{array}$ & Maps \\
\hline Carrol, 1993 & Way-finding abilities & Individuals' IQ \\
\hline Cornell et al, 1994 & Way-finding abilities & The age differences \\
\hline $\begin{array}{l}\text { Chen et al., 1994a; } \\
\text { 1996b; } 2009\end{array}$ & Way-finding abilities & Gender differences \\
\hline Lawton, 1996 & $\begin{array}{l}\text { Way-finding in an } \\
\text { unfamiliar } \\
\text { environment }\end{array}$ & Orientation, route, and building configuration \\
\hline Arthur et al., 1997 & Way-finding abilities & Gender differences \\
\hline Abu-Obeid, 1998 & Way-finding & Pictorial image of the building \\
\hline Passini et al., 1998 & Physical influences & The layout of the setting (environment spatial \\
\hline
\end{tabular}




\begin{tabular}{|c|c|c|}
\hline Allen,1999 & $\begin{array}{c}\text { that affected the way- } \\
\text { finding process }\end{array}$ & $\begin{array}{c}\text { content, its form, its organization, and its circulation). } \\
\text { quality of the environmental information } \\
\text { (architectural and graphic expression of information) }\end{array}$ \\
\hline $\begin{array}{c}\text { Murakoshi\& Kawai, } \\
\text { 2000 }\end{array}$ & $\begin{array}{c}\text { Maps, written directions, verbal communication, } \\
\text { visual communication as signs and colours, and } \\
\text { interaction with others }\end{array}$ \\
\hline $\begin{array}{c}\text { Dogu\&Erkip, 2000 } \\
\text { Baskaya et al., 2004 }\end{array}$ & $\begin{array}{c}\text { Legibility factors and } \\
\text { way-finding } \\
\text { Watial orientation } \\
\text { behaviour }\end{array}$ & $\begin{array}{c}\text { Architectural elements (entrances, horizontal and } \\
\text { vertical circulation, and key landmarks) }\end{array}$ \\
\hline $\begin{array}{c}\text { Muhl\& Hausen,2006 } \\
\text { Way-finding elements }\end{array}$ & $\begin{array}{c}\text { Familiarity with an environment } \\
\text { layout plan }\end{array}$ \\
\hline $\begin{array}{c}\text { Rousek\&Hallbeck, } \\
\text { 2011 }\end{array}$ & $\begin{array}{c}\text { The difference in } \\
\text { health \& way-finding } \\
\text { signs, kiosks and digital display devices), } \\
\text { oral elements and tactile elements (prominent boards, } \\
\text { writing Braille and special flooring) }\end{array}$ \\
\hline $\begin{array}{c}\text { Karimi\&Emami, } \\
2015\end{array}$ & $\begin{array}{c}\text { Diagonal elements, angled and curved avoided, split } \\
\text { the large open space into small parts, use of signs, } \\
\text { use flooring, lighting, texture, and improved tactile } \\
\text { and visual elements }\end{array}$ \\
\hline Way-finding abilities & Individual differences, gender, and age \\
\hline
\end{tabular}

Table 6. Individual factor results

\begin{tabular}{|c|c|c|c|c|c|c|c|}
\hline \multicolumn{2}{|c|}{ Age } & \multicolumn{2}{c|}{ Departments } & \multicolumn{2}{c|}{ Nationality } & \multicolumn{2}{c|}{ Health } \\
\hline categories & $\%$ & categories & $\%$ & categories & $\%$ & categories & $\%$ \\
\hline $18-20$ & 34.1 & Architecture & 54.5 & Jordanian & 93.2 & $\begin{array}{c}\text { Good } \\
\text { health }\end{array}$ & 93.2 \\
\hline $21-22$ & 18.2 & Civil & 38.6 & Others & 6.8 & Problems & 6.8 \\
\hline $23-24$ & 45.5 & Industrial & 6.8 & & & & \\
\hline $25-26$ & 2.3 & & & & & & \\
\hline
\end{tabular}

Table 7. The architectural elements

\begin{tabular}{|c|c|c|c|}
\hline Tools & Good availability $\%$ & Acceptable $\%$ & Not available \% \\
\hline \multicolumn{5}{|c|}{ A-The design language } \\
\hline Landmarks & 36.4 & 50 & 13.6 \\
\hline Landscape & 13.6 & 43.2 & 43.2 \\
\hline Pedestrian routes & 20.5 & 50.0 & 29.5 \\
\hline Symmetrical plan & 20.5 & 40.9 & 38.6 \\
\hline Building configuration & 15.9 & 52.3 & 31.8 \\
\hline \multicolumn{5}{|c|}{ B-Spatial organization system } \\
\hline Stairs & 34.1 & 47.7 & 18.2 \\
\hline Elevators & 11.4 & 50.0 & 38.6 \\
\hline Corridors & 36.4 & 54.5 & 29.5 \\
\hline Nods & 15.9 & 54.5 & 72.7 \\
\hline Colours & C-The sitting appearance & 68.2 \\
\hline Materials & 11.4 & 15.9 & 72.7 \\
\hline Decoration systems & 2.3 & 29.5 & 52.3 \\
\hline Textures & 0 & 27.3 & 54.5 \\
\hline Lighting systems & 6.8 & 40.9 & \\
\hline
\end{tabular}


Table 8. Circulation systems' position

\begin{tabular}{|c|c|c|c|}
\hline & Accessible \% & Need to search \% & Not accessible \% \\
\hline Stairways' position & 50 & 45.5 & 4.5 \\
\hline Elevators' position & 22.7 & 54.5 & 22.7 \\
\hline Entrances' position & 47.7 & 50 & 2.3 \\
\hline
\end{tabular}

Table 9. Visual communication elements

\begin{tabular}{|c|c|c|c|}
\hline Tools & Good availability $\%$ & Acceptable $\%$ & Not available \% \\
\hline Maps & 2.3 & 18.2 & 79.5 \\
\hline 'You Are Here' map & 2.3 & 9.1 & 88.6 \\
\hline Direction signs & 0 & 15.9 & 84.1 \\
\hline Written signs & 0 & 38.6 & 61.4 \\
\hline Painting guides & 4.5 & 15.9 & 79.5 \\
\hline Offices' Number & 65.9 & 22.7 & 11.4 \\
\hline Halls' Numbers & 63.6 & 13.6 & 22.7 \\
\hline Floors' Numbers & 59.1 & 25.0 & 15.9 \\
\hline Digital Display Device & 11.4 & 45.5 & 43.2 \\
\hline
\end{tabular}

Table 10.Audible communication tools

\begin{tabular}{|c|c|c|c|}
\hline Tools & Good availability \% & Acceptable \% & Not available \% \\
\hline Information stations & 2.3 & 11.4 & 86.4 \\
\hline Audible chimes inside elevators & 2.3 & 4.5 & 93.2 \\
\hline Audible Signs & 0 & 13.6 & 86.4 \\
\hline
\end{tabular}

Table 11.Tactile elements

\begin{tabular}{|c|c|c|c|}
\hline Tools & Good availability \% & Acceptable \% & Not available \% \\
\hline Writing Braille & 0 & 38.6 & 61.4 \\
\hline Special flooring & 0 & 6.8 & 93.2 \\
\hline Prominent boards & 0 & 6.8 & 93.2 \\
\hline
\end{tabular}

Table 12. Availability of the way-finding tools in Hajjawy for engineering technology

\begin{tabular}{ccc}
\hline $\begin{array}{c}\text { Well available } \\
\text { tools }\end{array}$ & Acceptably available tools & Not available tools \\
\hline Offices' Number & Landmarks & Colours \\
Halls' Numbers & Landscape & Materials \\
Floors' Numbers & Pedestrian routs & Decoration system \\
& Symmetrical plan & Textures \\
& Building configuration & Lighting systems \\
& Stairs & Maps \\
& Elevators & Corridors \\
& Nods & 'ou Are Here' map \\
& Digital Display Device & Written signs \\
& & Painting guides \\
& & Information stations \\
& & Audible chimes inside \\
& & Audible Signs \\
& & Writing Braille \\
& & Special flooring \\
& & Prominent boards \\
\hline tools & 10 tools & 16 tools \\
\hline
\end{tabular}




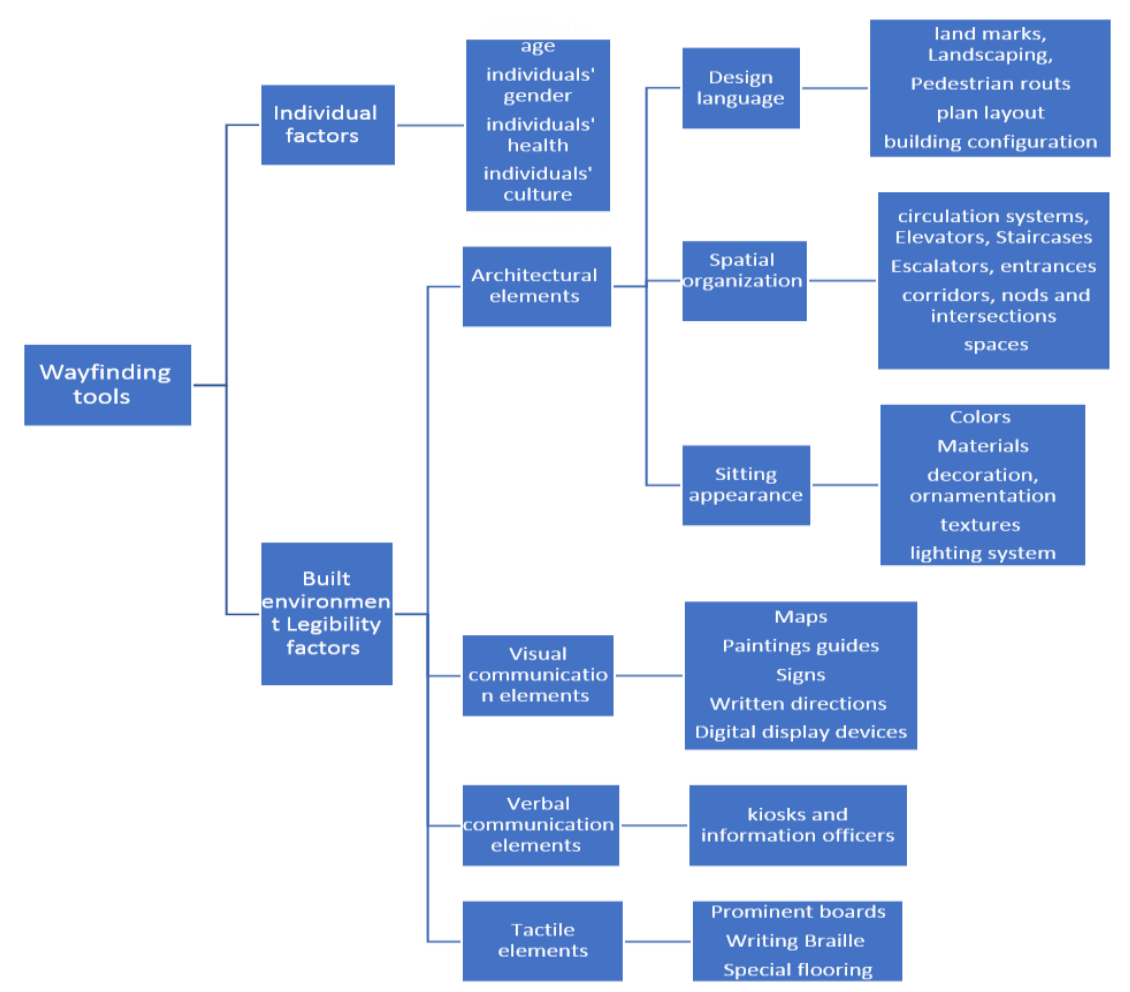

Figure 1, way-finding tools

\section{References}

Abu-Obeid, N. (1998). Abstract and Stenographic Imagery: The Effect of Environmental form on Way-finding. Journal of Environmental Psychology,18: 2 (159-17).

Allen, G. (1999) Spatial abilities, cognitive maps, and way-finding: Bases for individual differences in spatial cognition and behaviour. In R. G.

Hund, A., Minarik, J.(2009). Getting from Here to There: Spatial Anxiety, Way-finding Strategies, Direction Type, and Way-finding Efficiency, Spatial Cognition \& Computation, 6:3, 179 201, DOI: $10.1207 / \mathrm{s} 15427633 \mathrm{scc} 0603 \_1$

Anooshian, L.J., Young, D. (1981). Developmental Changes in Cognitive Maps of a Familiar Neighborhood. JSTOR, 52:1

Arthur, P., Passini, R. (1992). Wayfinding:People, Signs, and Architecture, Ontario: McGrawHill Ryerson Ltd.Reissued as a collector's edition in 2002 by Focus Strategic Communications, Inc.

Arthur,E.J., Hancok,P.A., Chrysler, S.T.(2010). The perception of spatial layout in real and virtual worlds, Ergonomics, 40:1, 69-77, DOI: 10.1080/001401397188387

Baskaya, A., Wilson, C., Özcan, Y. (2004). Way-finding in an Unfamiliar Environment, Different Spatial Settings of Two Polyclinics. Environment and Behavior, 36: 6 DOI: 10.1177/0013916504265445

Brandon, K. (2008). Way-finding, http://www.kellybrandondesign.com

Canter, D.V. (1996)Way-finding and signposting: Penance or prosthesis. In D. V. Canter (Ed.), Psychology in action (139-155). San Diego: Academic Press.

Carrol, J.B. (1993) Human cognitive abilities: A survey of factor-analytic studies. New York: Cambridge University Press.

Carpman, J.R.,Grant, M.A. (2001). Way-finding: a broad view. In R. B. Bechtel \& A. Ts'erts'man (Eds.), Handbook of environmental psychology (427-442) New York: J. Wiley.

Chen, L.H., Chang, C.,Chang, T. (2009).Gender differences in relation to way-finding strategies, navigational support design, and way-finding task difficulty. Journal of Environmental Psychology, 29: 220-226. Cornell EH, Heth CD, AlbertsDM (1994)Place recognition and way-finding by children and adults, Memory and Cognition 22 (633-643), 10.3758/BF03209249 
Dalton, R.C., Bafna, S. (2003). The syntactical image of the city: a reciprocal definition of spatial elements and spatial syntaxes, 4th International Space Syntax Symposium

Dellinger, B. (2010). Healing Environments. In C. Mc.Cullough (Ed.),Evidence Based Design for healthcare facilities (45-80), Indianapolis: Renee Wilmeth

Dogu, U.,Erkip, F. (2000).Spatial Factors Affecting Way-finding and Orientation, A Case Study in a Shopping Mall. Environment and Behavior, 32: 6 (731-755).

Downs Roger N.,Stea, D. (1973). Cognitive Maps and Spatial Behavior: Process and Products, in Image and Environment: Cognitive Mapping and Spatial Behavior, eds. Roger M. Downs, R. and David Stea, Chicago: Aldine, (8-26).

Downs Roger N., Stea, D.(1977). Naps in Minds:Reflections on Cognitive Mapping, New York: Harper\& Row.

Evans GW, Smith C,Pezdek K (1982) Cognitive maps and urban forms. Journal of the American Planning Association, 48, 232-244.

Evans, G., McCoy, M. (1998).When Buildings Don't Work: The Role of Architecture in Human Health, Journal of Environmental Psychology, 18: 85-94.

Garling, T., Lindberg, E.,Mantyla, T. (1983). Orientation in buildings: Effects of familiarity,visual access, and orientation aids. Journal of Applied Psychology, 68, 177-186.

Garling, T., Book, A., Lindberg, E. (1986). Spatial Orientation and Way-finding in the Designed Environment: A Conceptual Analysis and Some Suggestions for Post occupancy Evaluation, Journal of Architectural and Planning Research 3:1 (55-64)

Golledge, R.G. (1999). Way-finding Behavior: Cognitive Mapping and Other Spatial Processes. Johns Hopkins University Press,

Golledge, R. G. (2004). The Nature of Geographic Knowledge, Annals of the association of the American Geographers. 92:1(1-14).

Haq, S., Zimring, C. (2003). The Development of Topological Knowledge of Building Layouts. SAGE Journals

Hillier, B., Hanson, J. (1988).The Social Logic of Space, Cambridge: Cambridge University Press.

Holscher,C., Tenbrink, T., Wiener, J. M. (2011). Would you follow your own route description? Cognitive strategies in urban route planning. Journal of EnvironmentalPsychology, 121: 228-247

Huelat, B. J. (2007). Way-finding: Design for understanding. Concord, CA: Center for Health Design.

Hund, A. M., Padgitt, A. J. (2010).Direction giving and following in the service of way-finding in a complex indoor environment.Journal of Environmental Psychology, 30: 553-564

Jibestream (2014). eBook. https://www.jibestream.com/

Karimi, M.,Emami, A. (2015).Review on way-finding performance by identification key factors influence, Cumhuriyet Science Journal, 36:3

Kaplan, S. (1975). An informal model for the prediction of preference. In E. H. Zube, R. O.

Kearins, J.M. (1981).Visual spatial memory in Australian Aboriginal children of desert regions, Cognitive Psychology, 13:3 (434-460)

Lawton, M.P., Liebowitzand Charon, H. (1970). Physical Structure and the Behavior of Senile Patients following Ward Remodeling. SAGE journals.

Lawton, C. A. (1996).Strategies for indoor way-finding: The role of orientation. Journal of Environmental Psychology, 16, 137-145.

Lynch, K. (1960).The Image of the City, Cambridge, Massachusetts: MIT Press

Maguire, E. A.,Spiers, H.J. (2008).The dynamic nature of cognition during way-finding, Journal of Environmental Psychology 28:3(232-249)

Meilinger, T.,Knauff, M.,Bülthoff, H.H.(2008).Working Memory in Way-finding-A Dual Task Experiment in a Virtual City, COGNITIVE SCIENCE, a Multidisciplinary Journal, 32:4(755-770)

Muhl hausen, J. (2006). Way-finding is not signage, http://myhome.spu.edu/kgz/4209/article1.html

Murakoshi, S.,Kawai, M. (2000) Use of Knowledge and Heuristics for Way-finding in an Artificial Environment, SAGE Journals, 32:6

O' Neill, M. J. (1991). Effects of signage and floor plan configuration on way-finding accuracy. Environment and Behavior, 23, 553-574.

O'Neill, M. J.,Jasper, C. R.(1992). An evaluation of models of consumer spatial behavior using the environmentbehaviour paradigm. Environment and Behavior, 24, 411-440.

Passini, R. (1984). Way-finding in architecture. New York: Van Nostrand Rienhold. 
Passini, R. (1995). Spatial representations: A way-finding perspective. In T. Garling (Ed.), Urban Cognition (139150). London: Academic Press.

Passini, R. (1996). Way-finding design: Logic, application and some thoughts on universality. Design Studies, 17(319-331).

Passini, R., Rainville, C., Marchand, N., Joanette, Y. (1998).Way-finding and dementia: Some research findings and a new look at design. Journal of Architectural and Planning Research, 15, (133-151).

Peponis, J., Zimring, C.,Choi, Y. K. (1990). Finding the building in way-finding. Environmentand Behavior, 22, (555-590).

Raubal, M.,Winter, S. (2002).Enriching Way-finding Instructions with Local landmarks. International Conference on Geographic Information Science, 243-259

Rousek, J. B.,Hallbeck, M. S. (2011).The use of simulated visual impairment to identify hospital design elements that contribute to way-finding difficulties. International Journal of Industrial Ergonomics, 41: (447-458).

Salthouse, T.A. (1991).Mediation of Adult Age Differences in Cognition by Reductions in Working Memory and Speed of Processing, SAGE Journals, 2:3

Sims, M. (1991). Sign design. New York: Thames and Hudson.

Tolman, E. C. (1948).Cognitive Maps in Rats and Men, The Psychological Review, 55(4), 189-208

Weisman, J. (1981). Evaluating architectural legibility. Environment and Behavior, 13, 189-204.

Wener, R.,Kaminoff, R.(1983). Improving environmental information: Effects of signs on perceived crowding and behavior. Environment and Behavior, 15, (3-20). 